\title{
Reduction of perfluorinated compound content in fish cake and swimming crab by different cooking methods
}

\author{
Li Luo', Min-Joo Kim', Jihyun Park', Hee-Deuk Yang ${ }^{2}$, Younglim Kho², Myung-Sub Chung ${ }^{3}$ \\ and BoKyung Moon ${ }^{1 *}$ (D)
}

\begin{abstract}
Perfluorinated compounds (PFCs) are widely used in industries, and have become common environmental pollutants. Consumption of aquatic foods and its processed products can result in the accumulation and maintenance of PFCs in organs of human body, which can lead to toxic consequences and poisoning. The aim of this study was to evaluate the reducing effects of PFC contents in fish cake and swimming crab by different cooking conditions. Fish cake was processed with blanching, boiling, frying, stir-frying and swimming crab was pretreated with soaking and cooked by steaming and stewing. The change of PFCs were determined using LC-MS/MS. Boiling reduced the total PFCs in fish cake by up to $45.9 \%$. As for swimming crab, soaking, steaming and stewing have reduced $65.7 \%, 17.6 \%$ and $13.3 \%$ of PFCs, respectively. These results suggest that cooking method involving water addition and high-temperature heating would be effective at reducing PFCs (PFOA especially) in food.
\end{abstract}

Keywords: Perfluorinated compounds, Cooking method, Reduction, LC-MS/MS, Swimming crab, Fish cake

\section{Introduction}

Perfluorinated compounds (PFCs) are widely used in the processing of several industrial products such as varnishes, paper, and coating agents owing to their specific physical and chemical properties, including heat resistance, acid and alkali resistance, and hydrophobicity [1]. Leaked PFCs easily spread in nature, especially through water-containing substances [2], and are thus increasingly detected in drinking water and domestic water in densely populated areas [3]. Once these compounds enter the body, they will continue to accumulate and affect the organs, leading to serious disease or poisoning when accumulated at sufficient concentrations [4]. Among the common PFCs, perfluorooctanoic acid (PFOA) and perfluorooctane sulfonate (PFOS) are the most environmentally stable and detectable, and their

\footnotetext{
*Correspondence: bkmoon@cau.ac.kr

1 Department of Food and Nutrition, Chung-Ang University, 4726 Seodong-daero, Daedeok-myeon, Anseong-si, Gyeonggi-do 456-756, Korea

Full list of author information is available at the end of the article
}

half-life exceeds 41 years, thus representing a significant environmental and health hazard [5]. Squadrone et al. [6] reported that PFOA and PFOS were considered as developmental toxicants and could have negative effects on fertility. It has been reported that benchmark dose lower confidence level (BMDL) ${ }_{10}$ for PFOS and PFOA are $30.5 \mu \mathrm{g} / \mathrm{kg}$ b.w./day and $0.3 \mathrm{mg} / \mathrm{kg}$ b.w./day, respectively $[7,8]$ and the tolerable daily intake (TDI) for PFOS and PFOA are established as $150 \mathrm{ng} / \mathrm{kg}$ b.w./day and $1500 \mathrm{ng} /$ $\mathrm{kg}$ b.w./day, respectively [7].

Previous studies have shown that food sources, especially aquatic foods, are the main exposure pathways of PFCs to humans $[6,9]$. According to the total diet study in western countries (2009), diet was the main exposure pathway of PFCs to human and PFOS and PFOA were the two PFCs with the highest daily exposure [10]. Furthermore, a survey of PFCs exposure in US also showed that the ingestion of drinking water or food which contaminated with PFCs was the most important route of exposure for general population [11]. Koreans are major consumers of fish and processed fish products, and also 
use a variety of cooking methods to prepare seafood or its processed products. Since fish has been reported to contain higher levels of PFCs than other food items [11], fish cakes made from fish-based ingredients have become a high-risk source of PFCs for humans in the daily diet.

Swimming crab (Portunus trituberculatus) is one of the most important marine economic crabs and its production reached 605,632 tons in 2016, making it became one of the most common edible crab [12]. Swimming crab also has important economic value with a long history of consumption in South Korea [13]. Along with fish cake, swimming crab has ranked at the forefront of nationwide seafood consumption for the last several years according to the Korean National Food \& Nutrition Statistics report conducted by the Korea Health Industry Development Institute (2015) [14]. However, the high consumption of swimming crab is also accompanied by high-risk of health. Swimming crabs caught in the sea near Korea have been detected to contain a considerable amount of PFCs, with the main harmful substances detected being PFOS and PFOA [15]. Since the content of PFCs in ingredients, especially seafood and its processed products, directly threatens the health of consumers, increasing research attention has focused on the use of various cooking methods to reduce the PFCs in the corresponding ingredients, such as steaming, baking, and frying, among others [16]. However, there is still controversy related to these results, and effective cooking methods for PFC reduction remains unclear. Despite the high number of studies focused on PFC monitoring and exposure, including analysis of the concentration of the compound in various exposure sources, there is still an overall lack of data to support the effect of pretreatment and various cooking methods on the change of PFCs in food [17].

Therefore, this study aimed to analyze and evaluate the effects of different types of pretreatments and cooking methods on the changes of PFCs in fish cake and swimming crab, as the two great high-risk food sources for PFCs in Korea. The fish cake was blanched for different times as a pretreatment, and then cooked by boiling, frying, and stir-frying. Swimming crab was pretreated with soaking and then cooked according to the most commonly used cooking methods including steaming, boiling, and marinating. The effects of the pretreatments and cooking treatments on the change in the PFC content were analyzed using liquid chromatography-tandem mass spectrometry (LC-MS/MS).

\section{Materials and methods Chemicals}

A total of 19 PFCs were used as standards for the analysis (all purchased from Wellington Laboratories, Guelph,
ON, Canada): PFOA, PFOS, perfluorobutanoic acid (PFBA), perfluorpentanoic acid (PFPeA), perfluorhexanoic acid (PFHxA), perfluorheptanoic acid (PFHpA), perfluorononanoic acid (PFNA), perfluorodecanoic acid (PFDA), perfluoroundecanoic acid (PFUnDA), perfluorododecanoic acid (PFDoDA), perfluorotridecanoic acid (PFTrDA), perfluorotetradecanoic acid (PFTeDA), perfluorobutane sulfonate (PFBS), perfluorohexane sulfonate $(\mathrm{PFHxS})$, sodium perfluoro-1 heptanesulfonate (L-PFHpS), perfluorodecane sulfonate (PFDS), perfluorooctane sulfonamide (PFOSA), $N$-methylperfluoro-1 octanesulfonamido acetic acid ( $N$-MePFOSAA), and $N$-ethyl-perfluoro-1 octanesulfonamido acetic acid (N-EtPFOSAA).

Perfluoro- $n-\left[1,2,-{ }^{13} C_{2}\right]$ hexanoic acid $\left({ }^{13} \mathrm{C}_{2} \mathrm{PFHxA}\right)$, perfluoro- $n-\left[1,2,3,4-{ }^{13} \mathrm{C}_{4}\right]$ octanoicacid $\quad\left({ }^{13} \mathrm{C}_{4} \mathrm{PFOA}\right)$, perfluoro- $n-\left[1,2,3,4,5-{ }^{13} C_{5}\right]$ nonanoic acid $\left({ }^{13} \mathrm{C}_{5} \mathrm{PFNA}\right)$, perfluoro- $n-\left[1,2-{ }^{13} \mathrm{C}_{2}\right]$ decanoic acid $\left({ }^{13} \mathrm{C}_{2} \mathrm{PFDA}\right)$, perfluoro- $n-\left[1,2-{ }^{13} \mathrm{C}_{2}\right]$ undecanoic acid $\quad\left({ }^{13} \mathrm{C}_{2}\right.$ PFUDA $)$, perfluoro- $n-\left[1,2-{ }^{13} \mathrm{C}_{2}\right]$ dodecanoic acid $\left({ }^{13} \mathrm{C}_{2} \mathrm{PFDoA}\right)$, perfluoro-1-hexane $\left[{ }^{18} \mathrm{O}_{2}\right]$ sulfonic acid $\left({ }^{18} \mathrm{O}_{2} \mathrm{PFHxS}\right)$, perfluoro-1-[1,2,3,4- $\left.{ }^{13} \mathrm{C}_{4}\right]$ octanesulfonic acid $\left({ }^{13} \mathrm{C}_{4}\right.$ PFOS), perfluoro- $n-\left[1,2,3,4-{ }^{13} \mathrm{C}_{4}\right]$ butanoic acid $\left({ }^{13} \mathrm{C}_{4} \mathrm{PFBA}\right)$, perfluoro- $n-\left[1,2-{ }^{13} \mathrm{C}_{2}\right]$ tetradecanoic acid $\left({ }^{13} \mathrm{C}_{2} \mathrm{PFTeDA}\right)$, perfluoro- $n-\left[1,2,3,4-{ }^{13} \mathrm{C}_{4}\right]$ heptanoic acid $\left({ }^{13} \mathrm{C}_{4} \mathrm{PFHpA}\right)$, perfluoro- $n-\left[{ }^{13} \mathrm{C}_{5}\right]$ pentanoic acid $\left({ }^{13} \mathrm{C}_{5} \mathrm{PFPeA}\right)$, and sodium perfluoro-1-[2,3,4-1 $\left.{ }^{13} \mathrm{C}_{3}\right]$ butanesulfonate $\left({ }^{13} \mathrm{C}_{3} \mathrm{PFBS}\right)$ were also obtained from Wellington Laboratories and used as internal standards (IS).

Sodium bicarbonate $\left(\mathrm{NaHCO}_{3}\right)$, sodium carbonate anhydrous $\left(\mathrm{Na}_{2} \mathrm{CO}_{3}\right)$, tetrabutylammonium hydrogen sulfate (TBAHS), formic acid, ammonium acetate, protease, and lipase were purchased from Sigma Aldrich (St. Louis, MO, USA). Methyl-t-butyl ether (MTBE), hexane, methanol, acetonitrile, and hyperpure water were purchased from Burdick \& Jackson (Muskegon, MI, USA).

\section{Sample preparation Samples}

According to the sales statistics of the quarter, 4 different brands of fish cake that have the highest local sales rates were selected and purchased from a retail market in Anseong, Korea. An average weight of $200 \mathrm{~g}$ for each, total 100 swimming crabs were purchased from Solaepogu (Incheon, Korea). Soybean oil, two types of soy sauce (Korean style soy sauce and Japanese style soy sauce) and Korean radish were also purchased at the retail market in Anseong, Korea.

\section{Fish cake preparation}

Two Kilograms of fish cake from 4 brands (500 g each) were cut to a uniform size $\left(2 \times 10 \mathrm{~cm}^{2}\right)$ and fully mixed as a composite sample to avoid deviations 
from experimental results caused by brand differences. For the pretreatment, $200 \mathrm{~g}$ of the fish cake was blanched in boiled water for 5,10 , and $20 \mathrm{~s}$, respectively. For boiling, the fish cake (200 g) was boiled in $600 \mathrm{~mL}$ water for $20 \mathrm{~min}$, and then drained and collected for subsequent experiments. In addition, the fish cake $(200 \mathrm{~g})$ samples were fried for $90 \mathrm{~s}$ at $200^{\circ} \mathrm{C}$ in $500 \mathrm{~mL}$ of edible soybean oil. Finally, the stir-fried samples were prepared from $100 \mathrm{~g}$ of fish cake, which was lightly stir-fried with $8 \mathrm{~g}$ of edible soybean oil for 3 min.

\section{Swimming crab preparation}

For all pretreatments and cooking methods, swimming crabs that were caught in the western sea area of Korea in the same batch were combined into composite samples so as to reduce experimental error caused by individual differences.

To compare the effect of pretreatment on PFC changes, eight swimming crabs were cut into four pieces respectively and mixed into a composite sample, which was then divided into four parts evenly. One part was left untreated as a control group, and the other three parts were soaked in distilled water $(0 \%$ salt solution) or in a $10 \%$, or $15 \%$ salt solution for $1 \mathrm{~h}$. The soaked swimming crab pieces were then collected and used for PFC content analysis.

The cooking conditions design was followed recipes that recommended by the Rural Development Administration (RDA) of Korea [18] with slight modifications. For stewing, 5 swimming crabs were cut into four pieces with equal quantity respectively, the swimming crab pieces were boiled for $10 \mathrm{~min}$ in $2500 \mathrm{~mL}$ of boiled water with $500 \mathrm{~g}$ Korean radish blocks. Crab meat, broth and radish were collected respectively after cooking. For steaming, 5 full swimming crabs were placed in a steamer with $2000 \mathrm{~mL}$ water at the bottom and steamed for $15 \mathrm{~min}$ over high fire. The fire level was reduced and the crabs were steamed for another $5 \mathrm{~min}$. The heat was turned off and the pot was left to sit covered for $5 \mathrm{~min}$. Steamed crab meat and steamed water (water left in steamer after steaming) were collected separately for subsequent analysis.

All samples were stored at $-20{ }^{\circ} \mathrm{C}$ until PFC analysis. Following the methods of Del Gobbo et al. [16], non-polytetrafluoroethylene cutting boards were used to cut all ingredients. For cooking, a stainless-steel pan (24 cm diameter, $5 \mathrm{~cm}$ depth) was selected for stir-frying. A stainless-steel pan ( $26 \mathrm{~cm}$ diameter, $5 \mathrm{~cm}$ depth) and stainless-steel steamer pot (26 cm diameter) was used for frying and steaming, respectively.

\section{PFC analysis}

The extraction and analysis of PFCs were performed according to the method of Bang et al. [19]. In brief, the samples were homogenized with the same amount of distilled water through a food blender (Tefal, BL1401 KR, Rumilly, France). One gram of the homogenized samples was placed in a polypropylene tube, followed by the addition of $20 \mu \mathrm{L}$ of the IS solution mixture, $350 \mu \mathrm{L}$ protease, and $350 \mu \mathrm{L}$ lipase, and mixed thoroughly. To prepare the IS solution mixture, $500 \mu \mathrm{L}$ of MPFAC-C-ES (2 $\mu \mathrm{g} / \mathrm{mL}$, MPFBA, M5PFPeA, M5PFHxA, M4PFHpA, M8PFOA, M9PFNA, M6PFDA, M7PFUnDA, MPFDoDA, M2PFTeDA, M4PFBS, M3PFHxS, and M8PFOS) was mixed and dissolved well in $8.8 \mathrm{~mL}$ of methanol with $50 \mu \mathrm{L}$ of d3-N-MeFOSAA $(50 \mu \mathrm{g} / \mathrm{mL})$ and $50 \mu \mathrm{L}$ of d5- $N$-EtFOSAA $(50 \mu \mathrm{g} / \mathrm{mL})$. The final concentrations of the individual IS were as follows: d3- $N$-MeFOSAA and d5- $N$-EtFOSAA as $25 \mathrm{ng} / \mathrm{mL}$, MPFBA, M5PFPeA, M5PFHxA, M4PFHpA, M8PFOA, M9PFNA, M6PFDA, M7PFUnDA, MPFDoDA, M2PFTeDA, M4PFBS, M3PF$\mathrm{HxS}$, and M8PFOS as $10 \mathrm{ng} / \mathrm{mL}$. The mixed sample was then placed in an incubator (Ilsin, Shaking incubator $\mathrm{SH}-803 \mathrm{R}$, Korea) for $16 \mathrm{~h}$ at $37^{\circ} \mathrm{C}$ for hydrolysis.

The sample was mixed with $5 \mathrm{~mL}$ of hexane using a rotator (AG, FINEPCR, Rotator, Gyeonggi-do, Korea) for $15 \mathrm{~min}$. After centrifugation (Gemmy Industrial Corp., PLC-05, Taipei, Taiwan) at $3960 \times g$ for $5 \mathrm{~min}$, the supernatant was removed by a pipette and the entire process was repeated twice. Two milliliters of $\mathrm{NaHCO}_{3}(0.25 \mathrm{M})$, $2 \mathrm{~mL}$ of $\mathrm{Na}_{2} \mathrm{CO}_{3}(0.25 \mathrm{M})$, and $1 \mathrm{~mL}$ of TBAHS $(0.5 \mathrm{M})$ were added to the mixture and shaken well, followed by sonication (Bransonic, 5510R-DTH, Danbury, USA) for $10 \mathrm{~min}$ for extraction. The extract was obtained using a rotator for $30 \mathrm{~min}$ after adding $5 \mathrm{~mL}$ of MTBE, and centrifuged for 5 min using a high-speed centrifuge at 10,000 rpm. The supernatant was collected and placed into a new polypropylene tube, and concentrated using a rotatory evaporator (EYELA, CVE-3100, UT-1000, Tokyo, Japan) for $1 \mathrm{~h}$ at $40{ }^{\circ} \mathrm{C}$. The final concentrate was re-diluted with $200 \mu \mathrm{L}$ of acetonitrile and injected into the Agilent 1100 Series LC series LC-MS/MS system Agilent 1100 Series LC series (Agilent Technologies, Palo Alto, CA, USA) for chemical analysis. The system is equipped with an Imtackt CD-C C18 column $(3.0 \mu \mathrm{m}$ particle diameter, $2.0 \times 150 \mathrm{~mm}$, Imtakt, Kyoto, Japan), API 4000 spectrometer (Applied Biosystems, Foster City, CA, USA), and electrospray ionization source, which was operated in negative mode. The injection volume was 3 $\mu \mathrm{L}$ and the mobile phase comprised $5 \mathrm{mM}$ ammonium acetate with $0.02 \%$ formic acid in water (A) and methanol (B) at a flow rate of $200 \mu \mathrm{L} / \mathrm{min}$. The specific analysis conditions are shown in Table 1. 
Table 1 LC MS/MS conditions for PFCs analysis

\begin{tabular}{|c|c|c|c|c|c|c|c|}
\hline \multicolumn{6}{|l|}{ HPLC } & \multicolumn{2}{|l|}{ MS/MS } \\
\hline \multirow[t]{3}{*}{ Equipment } & \multicolumn{5}{|c|}{ CD-C C18 column $(3.0 \mu \mathrm{M}$ particle diameter, $2.0 \times 150 \mathrm{~mm})$} & lonization mode & ESI negative \\
\hline & \multicolumn{5}{|c|}{ API 4000 spectrometer } & Ion source gas 1 & 40 psi \\
\hline & \multicolumn{5}{|c|}{ Electrospray ionization (ESI) with negative mode } & Ion source gas 2 & 60 psi \\
\hline Mobile phase & \multicolumn{5}{|c|}{$\begin{array}{l}\text { A: } 5 \text { mM Ammonium acetate with } 0.02 \% \text { formic acid in water } \\
\text { B: Methanol }\end{array}$} & Curtain gas & 25 psi \\
\hline Injection volume & \multicolumn{5}{|l|}{$3 \mu \mathrm{L}$} & Ion spray voltage & $4500 \mathrm{~V}$ \\
\hline Flow rate & \multicolumn{5}{|l|}{$200 \mu \mathrm{L} / \mathrm{min}$} & Collision gas & $6 \mathrm{eV}$ \\
\hline \multirow[t]{3}{*}{ Gradient } & $0 \mathrm{~min}$ & $5 \min$ & $13 \min$ & $13.1 \mathrm{~min}$ & $25 \min$ & Temperature & $400^{\circ} \mathrm{C}$ \\
\hline & $70 \%$ & $0 \%$ & $0 \%$ & $70 \%$ & $70 \%$ & & \\
\hline & $30 \%$ & $100 \%$ & $100 \%$ & $30 \%$ & $30 \%$ & & \\
\hline
\end{tabular}

\section{Method validation}

The LC-MS/MS method for 19 PFCs analysis was validated in terms of limits of detection (LOD) and quantification (LOQ), linearity, accuracy, and precision. The linearity of the analytical method was evaluated by plotting 3 calibration curves using 9 different concentrations $(0.02,0.05,0.1,0.2,0.5,1,2,5,10 \mathrm{ng} / \mathrm{mL})$. To evaluate the sensitivity of the method, the LOD and LOQ values were calculated using the following equations: $\mathrm{LOD}=3.3 \times$ (standard deviation/slope of calibration curve) and $\mathrm{LOQ}=10 \times($ standard deviation/slope of calibration curve). Nineteen PFCs at three different concentration $(0.2,1.0,5.0 \mathrm{ng} / \mathrm{g})$ were analyzed with five replicates on the same day to determine the interday precision, and over different days to determine the intraday precision. Both precision values are expressed as relative standard deviations (RSD, \%).

\section{Statistical analysis}

The results are expressed as mean \pm standard deviation. Statistical analyses were performed using SigmaStat 2.03 software (SPSS Inc., Chicago, IL), and Duncan's multirange test was used to determine the significance of the differences in each measurement mean among groups; $p<0.05$ was considered statistically significant.

\section{Results and discussion \\ Method validation}

Analytical method for 19 PFCs was validated. Linearity was determined from triplicate analyses of 9 samples with concentrations in the range of $0.02-10 \mathrm{ng} / \mathrm{mL}$. The calibration curves showed linear regression equations with good correlation coefficients $\left(R^{2}>0.9976\right)$ for all 19 PFCs (Additional file 1: Table S1). The limit of detection (LOD) and limits of quantification (LOQ) ranged from 0.02 to $0.09 \mathrm{ng} / \mathrm{g}$ and 0.08 to $0.27 \mathrm{ng} / \mathrm{g}$, respectively (Additional file 1: Table S1). The precision is expressed by the relative standard deviation (\%RSD). The RSD values of interday variation were between 1.56 and $17.66 \%$, and the RSD values of intraday variation were between 2.63 and $13.33 \%$. The interday accuracy ranged from 78.61 to $118.30 \%$ in 19 PFCs, and intraday accuracy ranged from 78.41 to $117.02 \%$ (Additional file 1: Table S2).

\section{Effect of pretreatment and cooking on the content of PFCs in fish cake}

Blanching is a commonly used pretreatment before cooking, which can degrade toxic substances or reduce toxic chemical residues in food [20]. Pedreschi et al. [21] reported that the acrylamide content of blanched fried potato was significantly reduced compared to that of the control group without blanching. Therefore, blanching could be considered as a process to reduce health risks from the diet; however, there is a lack of relevant research to support the possibility of blanching to reduce PFCs in seafood products.

The changes of PFCs in fish cake after blanching and cooking are summarized in Table 2. Blanching was observed to cause a reduction in PFCs content of fish cake but the change was not significant. It is possible that the content of PFCs might continue to decrease over a longer blanching time, however, long-time blanching will ultimately affect the texture of fish cake, leading to a reduction in the quality of the ingredients. Therefore, blanching over $20 \mathrm{~s}$ was not treated in this study. Until now, there has been limited research conducted on the effect of cooking on the content of PFCs in food, and the results obtained are controversial. Fish, shellfish, and shrimp caught from the Mediterranean Sea showed PFCs increased after cooking by traditional Greek cooking methods [22]. In contrast, Del Gobbo et al. [16] reported that 17 PFCs in fish samples from Canada were effectively reduced after baking, boiling, and frying. As shown in Table 2, all cooking methods, including boiling, frying, and stir-frying, were effective to reduce the amount of PFCs in the fish cake significantly, but there 
Table 2 Change of PFCs ( $\mathbf{n g} / \mathbf{g})$ of fish cake by different treatment conditions

\begin{tabular}{|c|c|c|c|c|c|c|c|}
\hline \multirow[t]{2}{*}{ Compound } & \multirow[t]{2}{*}{ Control } & \multicolumn{3}{|c|}{ Blanching time } & \multirow[t]{2}{*}{ Boiling } & \multirow[t]{2}{*}{ Frying } & \multirow[t]{2}{*}{ Stir-frying } \\
\hline & & $5 \mathrm{~s}$ & $10 \mathrm{~s}$ & $20 \mathrm{~s}$ & & & \\
\hline PFOA & $0.20 \pm 0.07^{a}$ & $0.17 \pm 0.01^{\mathrm{a}}$ & $0.16 \pm 0.02^{\mathrm{a}}$ & $0.19 \pm 0.02^{\mathrm{a}}$ & $0.06 \pm 0.01^{b}$ & $0.06 \pm 0.01^{b}$ & $0.07 \pm 0.01^{b}$ \\
\hline PFOS & $1.29 \pm 0.15^{\mathrm{a}}$ & $1.19 \pm 0.07^{\mathrm{a}}$ & $0.94 \pm 0.07^{b}$ & $0.87 \pm 0.08^{b}$ & $0.93 \pm 0.02^{b}$ & $1.16 \pm 0.11^{\mathrm{ab}}$ & $1.15 \pm 0.13^{\mathrm{ab}}$ \\
\hline PFBA & $0.06 \pm 0.02^{b}$ & $0.08 \pm 0.07^{a}$ & $0.11 \pm 0.01^{\mathrm{ab}}$ & $0.23 \pm 0.16^{\mathrm{a}}$ & $0.05 \pm 0.02^{b}$ & $0.07 \pm 0.00^{\mathrm{ab}}$ & $0.10 \pm 0.01^{\mathrm{a}}$ \\
\hline PFPeA & $0.13 \pm 0.01^{\mathrm{a}}$ & $0.12 \pm 0.02^{\mathrm{ab}}$ & ND & ND & ND & ND & ND \\
\hline PFHXA & ND & $0.07 \pm 0.00^{\mathrm{a}}$ & $0.08 \pm 0.01^{\mathrm{a}}$ & ND & ND & ND & ND \\
\hline PFHpA & $0.08 \pm 0.03^{\mathrm{a}}$ & $0.09 \pm 0.01^{\mathrm{a}}$ & $0.09 \pm 0.01^{\mathrm{a}}$ & $0.07 \pm 0.01^{\mathrm{a}}$ & ND & ND & ND \\
\hline PFNA & $0.07 \pm 0.01^{a}$ & $0.06 \pm 0.01^{\mathrm{a}}$ & $0.04 \pm 0.01^{b}$ & $0.06 \pm 0.01^{\mathrm{a}}$ & ND & $0.03 \pm 0.01^{b}$ & $0.03 \pm 0.00^{b}$ \\
\hline PFDA & $0.07 \pm 0.02^{\mathrm{a}}$ & $0.06 \pm 0.02^{\mathrm{a}}$ & $0.07 \pm 0.00^{\mathrm{a}}$ & $0.05 \pm 0.03^{\mathrm{a}}$ & ND & $0.04 \pm 0.01^{b}$ & $0.05 \pm 0.00^{b}$ \\
\hline PFUnDA & $0.23 \pm 0.04^{\mathrm{a}}$ & $0.20 \pm 0.08^{\mathrm{a}}$ & $0.19 \pm 0.01^{\mathrm{a}}$ & $0.17 \pm 0.02^{\mathrm{a}}$ & $0.15 \pm 0.01^{b}$ & $0.18 \pm 0.01^{b}$ & $0.17 \pm 0.02^{b}$ \\
\hline PFDoDA & $0.09 \pm 0.02^{\mathrm{a}}$ & $0.10 \pm 0.01^{\mathrm{a}}$ & $0.06 \pm 0.03^{\mathrm{ab}}$ & $0.06 \pm 0.00^{b}$ & $0.03 \pm 0.00^{b}$ & $0.03 \pm 0.01^{b}$ & $0.04 \pm 0.00^{b}$ \\
\hline PFTrDA & $0.43 \pm 0.06^{\mathrm{a}}$ & $0.54 \pm 0.22^{\mathrm{a}}$ & $0.36 \pm 0.18^{\mathrm{a}}$ & $0.27 \pm 0.05^{\mathrm{a}}$ & $0.31 \pm 0.05^{\mathrm{ab}}$ & $0.36 \pm 0.10^{\mathrm{ab}}$ & $0.28 \pm 0.07^{b}$ \\
\hline PFTeDA & $0.24 \pm 0.17^{a}$ & $0.12 \pm 0.00^{\mathrm{a}}$ & $0.15 \pm 0.03^{\mathrm{a}}$ & $0.09 \pm 0.09^{a}$ & $0.07 \pm 0.05^{\mathrm{ab}}$ & ND & $0.05 \pm 0.02^{b}$ \\
\hline PFBS & ND & ND & ND & $0.07 \pm 0.04^{\mathrm{a}}$ & ND & ND & ND \\
\hline PFHxS & $0.06 \pm 0.03^{\mathrm{a}}$ & $0.06 \pm 0.01^{\mathrm{a}}$ & $0.10 \pm 0.04^{\mathrm{a}}$ & $0.06 \pm 0.00^{\mathrm{a}}$ & ND & ND & ND \\
\hline L-PFHpS & ND & ND & ND & ND & ND & ND & ND \\
\hline PFDS & $0.01 \pm 0.01^{\mathrm{a}}$ & $0.02 \pm 0.01^{\mathrm{a}}$ & ND & ND & ND & ND & ND \\
\hline PFOSA & ND & ND & ND & ND & ND & ND & ND \\
\hline MePFOSAA & ND & ND & ND & ND & ND & ND & ND \\
\hline EtPFOSAA & ND & ND & ND & ND & ND & ND & ND \\
\hline Total & $2.96 \pm 0.65^{a}$ & $2.88 \pm 0.44^{\mathrm{a}}$ & $2.34 \pm 0.34^{\mathrm{a}}$ & $2.20 \pm 0.31^{\mathrm{a}}$ & $1.60 \pm 0.16^{b}$ & $1.93 \pm 0.19^{b}$ & $1.94 \pm 0.07^{b}$ \\
\hline
\end{tabular}

PFOA: Perfluorooctanoic acid; PFOS: perfluorooctane sulfonate; PFBA: perfluorobutanoic acid; PFPeA: perfluorpentanoic acid; PFHxA: perfluorhexanoic acid; PFHpA: perfluorheptanoic acid; PFNA: perfluorononanoic acid; PFDA: perfluorodecanoic acid; PFUnDA: perfluoroundecanoic acid; PFDoDA: perfluorododecanoic acid; PFTrDA: perfluorotridecanoic acid; PFTeDA: perfluorotetradecanoic acid; PFBS: perfluorobutane sulfonate; PFHxS: perfluorohexane sulfonate; L-PFHpS: sodium perfluoro-1 heptanesulfonate; PFDS: perfluorodecane sulfonate; PFOSA: perfluorooctane sulfonamide; MePFOSAA: methylperfluoro-1 octanesulfonamido acetic acid; EtPFOSAA: ethyl-perfluoro-1 octanesulfonamido acetic acid

$a, b$ Values with different letters within a row indicate a statistically significant difference $(p<0.05)$

was no significant difference among the three cooking methods. PFOS was the most abundant PFC detected in fish cakes, and its amount was also the highest even after cooking. Del Gobbo et al. [16] also reported that PFOS was the most abundant PFC detected in aquatic organisms. Boiling was found to show the most significant reduction in PFCs. After boiling, the PFOA in the fish cake was reduced by $70 \%$ (from 0.2 to $0.06 \mathrm{ng} / \mathrm{g}$ ), the PFOS decreased by $27.9 \%$ (from 1.29 to $0.93 \mathrm{ng} / \mathrm{g}$ ), and total PFCs were reduced by $45.9 \%$ compared to those of the uncooked fish cakes.

Thus, boiling, frying, and stir-frying are considered to be effective cooking methods for reducing the content of PFCs in fish cakes, and boiling is particularly recommended as the preferred cooking method for reducing health risks caused by PFCs.

\section{Effect of pretreatment and cooking on the content of PFCs in swimming crab Effect of soaking}

The change in the PFC content of swimming crabs was observed after soaking in distilled water $(0 \%$ salt solution) and in a 10\%, $15 \%$ salt solution for an hour. The results are shown in Table 3. All the PFCs in swimming crab meat were significantly reduced after soaking in d-water compared to control group, except for PFBS and PFDS, whose changes were not significant. Total PFCs decreased by $48.1 \%$ (from 32.4 to $16.8 \mathrm{ng} / \mathrm{g}$ ), and PFOA showed the highest rate of decreasing up to 65.7\% (from 12.5 to $4.3 \mathrm{ng} / \mathrm{g}$ ). PFCs were also observed to be significantly reduced by soaking in $10 \%$ and $15 \%$ salt solutions, which were reduced by $42.9 \%$ (from 32.4 to $18.5 \mathrm{ng} / \mathrm{g}$ ) and $42.3 \%$ (from 32.4 to $18.7 \mathrm{ng} / \mathrm{g}$ ), respectively.

It is known that PFCs, represented by PFOA and PFOS, are extremely high water-soluble [23, 24]. It is reasonable to infer that the reduction of PFCs observed in crab pieces might be caused by diffusion of tissue fluid with PFCs from crab meat into water.

Salinity of $10 \%$, which represent the salinity of lowsalt soy sauce, and $15 \%$ salt solution, which represent the salinity of soy sauce, were selected and their effect of reduction of PFCs were lower than d-water. Therefore, soaking in water as a pretreatment is considered to be a 
Table 3 Effect of soaking for $1 \mathrm{~h}$ in different concentrations of salt solution on the reducing the PFCs (ng/g) in swimming crab

\begin{tabular}{|c|c|c|c|c|}
\hline \multirow[t]{2}{*}{ Compound } & \multirow[t]{2}{*}{ Control } & \multicolumn{3}{|l|}{ Crab meat } \\
\hline & & Distilled water & $10 \%$ salt solution & $15 \%$ salt solution \\
\hline PFOA & $12.49 \pm 0.90^{a}$ & $4.28 \pm 0.11^{c}$ & $6.14 \pm 0.22^{b}$ & $5.83 \pm 0.22^{b}$ \\
\hline PFOS & $7.68 \pm 0.10^{\mathrm{a}}$ & $5.16 \pm 0.13^{b}$ & $3.72 \pm 0.09^{c}$ & $5.10 \pm 0.14^{b}$ \\
\hline PFBA & $0.73 \pm 0.02^{\mathrm{a}}$ & $0.52 \pm 0.02^{b}$ & $0.45 \pm 0.03^{c}$ & $0.49 \pm 0.05^{b c}$ \\
\hline PFPeA & $0.09 \pm 0.01^{\mathrm{a}}$ & ND & $0.11 \pm 0.00^{\mathrm{ab}}$ & $0.13 \pm 0.02^{\mathrm{a}}$ \\
\hline PFHxA & $0.06 \pm 0.00^{\mathrm{a}}$ & ND & ND & $0.05 \pm 0.01^{b}$ \\
\hline PFHpA & $0.41 \pm 0.01^{\mathrm{a}}$ & $0.1 \pm 0.00^{d}$ & $0.16 \pm 0.01^{b}$ & $0.12 \pm 0.01^{c}$ \\
\hline PFNA & $1.87 \pm 0.08^{\mathrm{a}}$ & $0.97 \pm 0.07^{c}$ & $1.07 \pm 0.01^{c}$ & $1.35 \pm 0.02^{b}$ \\
\hline PFDA & $0.92 \pm 0.05^{\mathrm{a}}$ & $0.63 \pm 0.05^{b}$ & $0.52 \pm 0.02^{c}$ & $0.63 \pm 0.02^{b}$ \\
\hline PFUnDA & $1.54 \pm 0.02^{\mathrm{a}}$ & $0.94 \pm 0.04^{c}$ & $1.12 \pm 0.02^{b}$ & $0.84 \pm 0.03^{d}$ \\
\hline PFDoDA & $0.61 \pm 0.02^{\mathrm{a}}$ & $0.26 \pm 0.01^{c}$ & $0.31 \pm 0.01^{b}$ & $0.25 \pm 0.01^{c}$ \\
\hline PFTrDA & $2.42 \pm 0.25^{\mathrm{a}}$ & $1.69 \pm 0.07^{b}$ & $1.76 \pm 0.12^{b}$ & $1.33 \pm 0.03^{c}$ \\
\hline PFTeDA & $0.68 \pm 0.03^{\mathrm{a}}$ & $0.38 \pm 0.01^{c}$ & $0.43 \pm 0.03^{b}$ & $0.38 \pm 0.01^{c}$ \\
\hline PFBS & $0.08 \pm 0.01^{\mathrm{a}}$ & $0.09 \pm 0.01^{\mathrm{a}}$ & $0.06 \pm 0.01^{b}$ & ND \\
\hline PFHXS & $0.47 \pm 0.02^{\mathrm{a}}$ & $0.15 \pm 0.01^{c}$ & $0.19 \pm 0.02^{b}$ & $0.18 \pm 0.02^{b c}$ \\
\hline L-PFHpS & ND & ND & ND & $0.10 \pm 0.01^{\mathrm{a}}$ \\
\hline PFDS & $0.25 \pm 0.10^{\mathrm{a}}$ & $0.25 \pm 0.06^{\mathrm{a}}$ & $0.12 \pm 0.04^{\mathrm{a}}$ & $0.17 \pm 0.05^{\mathrm{a}}$ \\
\hline PFOSA & $1.99 \pm 0.22^{\mathrm{a}}$ & $1.26 \pm 0.12^{c}$ & $1.91 \pm 0.14^{\mathrm{ab}}$ & $1.69 \pm 0.07^{b}$ \\
\hline MePFOSAA & ND & ND & ND & ND \\
\hline EtPFOSAA & ND & ND & ND & ND \\
\hline Total & $32.38 \pm 0.66^{a}$ & $16.79 \pm 0.66^{c}$ & $18.49 \pm 0.46^{b}$ & $18.68 \pm 0.42^{b}$ \\
\hline
\end{tabular}

ND: Not detected

PFOA: Perfluorooctanoic acid; PFOS: perfluorooctane sulfonate; PFBA: perfluorobutanoic acid; PFPeA: perfluorpentanoic acid; PFHxA: perfluorhexanoic acid; PFHpA: perfluorheptanoic acid; PFNA: perfluorononanoic acid; PFDA: perfluorodecanoic acid; PFUnDA: perfluoroundecanoic acid; PFDoDA: perfluorododecanoic acid; PFTrDA: perfluorotridecanoic acid; PFTeDA: perfluorotetradecanoic acid; PFBS: perfluorobutane sulfonate; PFHxS: perfluorohexane sulfonate; L-PFHpS: sodium perfluoro-1 heptanesulfonate; PFDS: perfluorodecane sulfonate; PFOSA: perfluorooctane sulfonamide; MePFOSAA: methylperfluoro-1 octanesulfonamido acetic acid; EtPFOSAA: ethyl-perfluoro-1 octanesulfonamido acetic acid

a-d With different letters within a row indicate a statistically significant difference $(p<0.05)$

recommendable method that could effectively reduce the PFCs content in swimming crab.

\section{Effect of steaming}

The results of steaming on the change of PFCs in swimming crab are shown in Fig. 1. PFOA was the most abundant PFCs in crab meat at $22.2 \mathrm{ng} / \mathrm{g}$, which accounted for $60.7 \%$ of the total content. PFOA is one of the most highly detectable PFC pollutants in environmental water, which is mainly attributed to its considerable watersolubility (about 3 times higher than PFOS) [25]. PFOA showed the most significant reduction after steaming compared to other PFCs, from 22.2 to $15.0 \mathrm{ng} / \mathrm{g}$, reaching a $32.6 \%$ decrease. The total content of PFCs in swimming crab meat significantly decreased from 36.6 to $30.1 \mathrm{ng} / \mathrm{g}$, which corresponded to an increase in water after steaming. The amount of total PFCs detected in remaining water increased from N.D. (not detected) to $4.8 \mathrm{ng} / \mathrm{mL}$ after steaming.
Steaming is a commonly used cooking method for crab in Asia. During the steaming process, the water vapor can permeate through the ingredients and is condensed down, so that the steaming water reflows into the boiling water. This up-and-down cycle can remove the water-soluble harmful substances in food, and the high temperature can increase their solubility or accelerate the volatilization [26]. Therefore, steaming could help PFCs, especially those that are water-soluble, to be eluted from swimming crab meat into the water in steamer.

PFCs have been found to actively combine with proteins in the organism and can directly invade tissues, including the blood and liver, becoming stably attached and subsequently accumulate [9]. Previous studies have shown that the bio-acceptability of major pollutants in seafood such as PFCs (PFUnA) and brominated flame retardants (BDE47, BDE100, $\alpha-\mathrm{HBCD}$ ) was significantly reduced compared to that of raw mullet after a steaming process, which was mainly attributed to the effect of steam in causing loss of digestible proteins in seafood, or 


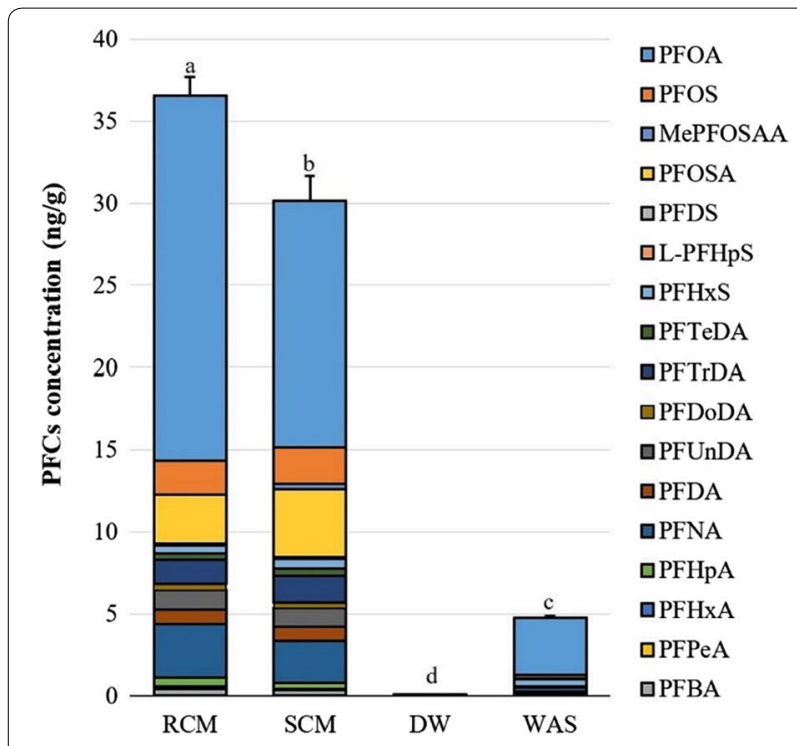

Fig. 1 Changes in composition of perfluorinated compounds in $c r a b$ meat and boiled water after steaming. Values with different letters indicate a statistically significant difference $(p<0.05)$. RCM: Raw crab meat; SCM: steamed crab meat; DW: distilled water; WAS: distilled water after steaming with crab; PFOA: perfluorooctanoic acid; PFOS: perfluorooctane sulfonate; PFBA: perfluorobutanoic acid; PFPeA: perfluorpentanoic acid; PFHXA: perfluorhexanoic acid; PFHpA: perfluorheptanoic acid; PFNA: perfluorononanoic acid; PFDA: perfluorodecanoic acid; PFUnDA: perfluoroundecanoic acid; PFDoDA: perfluorododecanoic acid; PFTrDA: perfluorotridecanoic acid; PFTeDA: perfluorotetradecanoic acid; PFBS: perfluorobutane sulfonate; PFHxS: perfluorohexane sulfonate; L-PFHpS: sodium perfluoro-1 heptanesulfonate; PFDS: perfluorodecane sulfonate; PFOSA: perfluorooctane sulfonamide; MePFOSAA: methylperfluoro-1 octanesulfonamido acetic acid; EtPFOSAA: ethyl-perfluoro-1 octanesulfonamido acetic acid

thermal degradation of chemical substances [27]. Similarly, Barbosa et al. [28] reported that levels of PFUnA, PFDoA, PFDcA, and PFOS in seafood decreased by an average of $33.5 \%$ after steaming. Like other toxic substances, PFCs have high biological affinity for proteins, which result in their accumulation in organisms and make them difficult to be discharged. Thus, since hightemperature steam can denature the protein or disrupt parts of tissue proteins, it is inferred that the PFCs contained within these components might be discharged into the cooking media, leading to the reduction.

\section{Effect of stewing}

Changes of PFCs by stewing are shown in Table 4. LC/ MS/MS chromatograms of perfluorinated compounds in standard solution (A) and broth boiled with crab meat (B) are shown in Fig. 2. The content of PFOA in swimming crab meat decreased significantly after stewing, from 20.8 to $16.8 \mathrm{ng} / \mathrm{g}$, reaching a decrease of $19.3 \%$, which was much higher than the $8.6 \%$ reduction in PFOS.
The hydrophilicity of PFOA is much higher than that of PFOS, and PFOA is more easily absorbed by organisms and shows a high level of transferability by water [29]. Compared with boiled water, the content of PFCs in the boiled broth increased from 0.03 to $28.3 \mathrm{ng} / \mathrm{mL}$ with the addition of swimming crab. The increase in total PFCs in the broth and the reduction in boiled swimming crab meat were both statistically significant. Interestingly, a significant increase in the content of PFCs was detected in the radish stewed with crab, from 0.3 to $3.8 \mathrm{ng} / \mathrm{g}$ (14 times increase compared to control group), and PFOA accounted for $84.7 \%$ of this increase.

Korean radish was used in the experiment, and being cooked by boiling is one of the methods to maximize its nutritional efficiency when it is consumed. Previous study has shown that cooking can release more nutrients at the process [30]. In addition, the lignin which richly contained in the radish is used as a low-cost absorbent agent to remove pollutants from water in industrial applications [31]. In view of the physical changes of radish occurred after stewing and its containing various natural ingredients with effective reduction of pollutants in diet, also based on the results of this experiment, it could be understood that PFCs, especially PFOA, partially transferred from the swimming crab meat to the radish during the stewing process and became adsorbed into the radish owing to its considerable fiber pore structure. Based on the present results, stewing with Korean radish as high-fiber ingredients appears to be an effective cooking method to reduce the content of PFCs in the primary ingredients, while simultaneously increasing the nutritional value of the dish. Moreover, the reaction temperature was previously reported to be the most important influencing factor on the efficiency of PFOA removal [32]. It could be inferred that a cooking method involving water addition and high-temperature heating would be very effective at reducing PFOA in food. Based on our results, the PFC content in swimming crab meat was considered to be effectively reduced using proper cooking methods and accessory ingredients with a high fiber content.

The tolerable daily intake (TDI) for PFOS and PFOA are established as $150 \mathrm{ng} / \mathrm{kg}$ b.w./day and $1500 \mathrm{ng} /$ $\mathrm{kg}$ b.w./day, respectively [7]. Based on the results from Korea National Health and Nutrition Examination Survey [33], the dietary exposure of PFOS from fish cake and swimming crab are estimated as $0.094 \mathrm{ng} / \mathrm{kg}$ b.w./day and $0.200 \mathrm{ng} / \mathrm{kg}$ b.w./day, respectively. The dietary exposure of PFOA from fish cake and swimming crab is estimated as $0.014 \mathrm{ng} / \mathrm{kg}$ b.w./day and $0.326 \mathrm{ng} / \mathrm{kg}$ b.w./day, respectively. Therefore, daily consumption of fish cake and swimming crab with normal level was considerably lower than the threshold that may cause harm to human. 
Table 4 Efficacy of stewing on reducing the PFC concentrations in swimming crab

\begin{tabular}{|c|c|c|c|c|c|c|c|}
\hline \multirow[t]{2}{*}{ Compound } & \multicolumn{2}{|c|}{ Crab meat (ng/g) } & \multicolumn{2}{|l|}{ Broth (ng/mL) } & \multicolumn{3}{|c|}{ Korean radish (ng/g) } \\
\hline & Raw & $\begin{array}{l}\text { Boiled } \\
\text { with radish }\end{array}$ & $\begin{array}{l}\text { Boiled } \\
\text { without crab }\end{array}$ & $\begin{array}{l}\text { Boiled } \\
\text { with crab }\end{array}$ & Raw & $\begin{array}{l}\text { Boiled } \\
\text { without crab }\end{array}$ & $\begin{array}{l}\text { Boiled } \\
\text { with crab }\end{array}$ \\
\hline PFOA & $20.79 \pm 0.17^{a}$ & $16.77 \pm 0.42^{b}$ & ND & $21.69 \pm 0.45^{\mathrm{a}}$ & ND & ND & $3.21 \pm 0.19^{a}$ \\
\hline PFOS & $0.81 \pm 0.02^{\mathrm{a}}$ & $0.74 \pm 0.03^{b}$ & ND & $0.65 \pm 0.00^{\mathrm{a}}$ & ND & ND & ND \\
\hline PFBA & $0.14 \pm 0.01^{\mathrm{a}}$ & $0.04 \pm 0.01^{b}$ & ND & $0.46 \pm 0.03^{\mathrm{a}}$ & $0.10 \pm 0.02^{\mathrm{a}}$ & $0.16 \pm 0.08^{\mathrm{a}}$ & $0.14 \pm 0.01^{\mathrm{a}}$ \\
\hline PFPeA & ND & ND & ND & $0.16 \pm 0.01^{\mathrm{a}}$ & ND & ND & ND \\
\hline PFHXA & ND & ND & ND & $0.10 \pm 0.01^{\mathrm{a}}$ & ND & ND & ND \\
\hline PFHpA & $0.37 \pm 0.03^{\mathrm{a}}$ & $0.32 \pm 0.01^{b}$ & ND & $0.54 \pm 0.01^{\mathrm{a}}$ & ND & ND & $0.11 \pm 0.00^{\mathrm{a}}$ \\
\hline PFNA & $2.89 \pm 0.02^{\mathrm{a}}$ & $2.30 \pm 0.03^{b}$ & ND & $1.90 \pm 0.01^{\mathrm{a}}$ & ND & ND & $0.22 \pm 0.01^{\mathrm{a}}$ \\
\hline PFDA & $0.66 \pm 0.02^{\mathrm{a}}$ & $0.57 \pm 0.02^{b}$ & ND & $0.39 \pm 0.03^{\mathrm{a}}$ & ND & ND & ND \\
\hline PFUnDA & $0.93 \pm 0.01^{\mathrm{a}}$ & $0.79 \pm 0.02^{b}$ & ND & $0.51 \pm 0.01^{\mathrm{a}}$ & ND & ND & ND \\
\hline PFDoDA & $0.25 \pm 0.02^{\mathrm{a}}$ & $0.23 \pm 0.01^{b}$ & ND & $0.11 \pm 0.01^{\mathrm{a}}$ & ND & ND & ND \\
\hline PFTrDA & $1.12 \pm 0.06^{\mathrm{a}}$ & $1.38 \pm 0.09^{b}$ & ND & $0.60 \pm 0.02^{\mathrm{a}}$ & ND & ND & ND \\
\hline PFTeDA & $0.28 \pm 0.01^{\mathrm{a}}$ & $0.26 \pm 0.02^{\mathrm{a}}$ & ND & $0.11 \pm 0.00^{\mathrm{a}}$ & ND & $0.09 \pm 0.03^{\mathrm{a}}$ & ND \\
\hline PFBS & ND & ND & ND & $0.20 \pm 0.02^{\mathrm{a}}$ & $0.12 \pm 0.05^{\mathrm{a}}$ & ND & ND \\
\hline PFHXS & $0.48 \pm 0.03^{\mathrm{a}}$ & $0.33 \pm 0.03^{b}$ & ND & $0.37 \pm 0.01^{\mathrm{a}}$ & ND & ND & $0.07 \pm 0.01^{a}$ \\
\hline L-PFHpS & ND & ND & ND & ND & ND & ND & ND \\
\hline PFDS & $0.04 \pm 0.01^{\mathrm{a}}$ & $0.04 \pm 0.01^{b}$ & ND & $0.03 \pm 0.02^{\mathrm{a}}$ & $0.02 \pm 0.00^{\mathrm{a}}$ & ND & $0.01 \pm 0.00^{\mathrm{a}}$ \\
\hline PFOSA & $1.54 \pm 0.09^{\mathrm{a}}$ & $2.55 \pm 0.19^{b}$ & ND & $0.47 \pm 0.02^{\mathrm{a}}$ & ND & ND & ND \\
\hline MePFOSAA & ND & ND & ND & ND & ND & ND & ND \\
\hline EtPFOSAA & ND & ND & ND & ND & ND & ND & ND \\
\hline Total & $30.33 \pm 0.10^{\mathrm{a}}$ & $26.30 \pm 0.61^{b}$ & ND & $28.28 \pm 0.43^{\mathrm{a}}$ & $0.27 \pm 0.01^{\mathrm{a}}$ & $0.25 \pm 0.03^{\mathrm{a}}$ & $3.79 \pm 0.13^{b}$ \\
\hline
\end{tabular}

PFOA: Perfluorooctanoic acid; PFOS: perfluorooctane sulfonate; PFBA: perfluorobutanoic acid; PFPeA: perfluorpentanoic acid; PFHxA: perfluorhexanoic acid; PFHpA: perfluorheptanoic acid; PFNA: perfluorononanoic acid; PFDA: perfluorodecanoic acid; PFUnDA: perfluoroundecanoic acid; PFDoDA: perfluorododecanoic acid; PFTrDA: perfluorotridecanoic acid; PFTeDA: perfluorotetradecanoic acid; PFBS: perfluorobutane sulfonate; PFHxS: perfluorohexane sulfonate; L-PFHpS: sodium perfluoro-1 heptanesulfonate; PFDS: perfluorodecane sulfonate; PFOSA: perfluorooctane sulfonamide; MePFOSAA: methylperfluoro-1 octanesulfonamido acetic acid; EtPFOSAA: ethyl-perfluoro-1 octanesulfonamido acetic acid

$a, b$ Values with different letters within a row indicate a statistically significant difference $(p<0.05)$

\section{Conclusions}

In this study, fish cakes and swimming crabs as two typical foods with large consumption were processed using current common pretreatments and cooking methods, referred to Korean recipes, for exploring the effect of cooking treatments on the change of PFC contents. After cooking, the greatest reduction of PFCs in fish cake was achieved with boiling (45.9\%), followed by frying (34.8\%) and stir-frying (34.5\%). Swimming crab pieces soaked in d-water, $10 \%$ and $15 \%$ salt solution for $1 \mathrm{~h}$ have shown reduction in PFCs content by $65.7 \%, 42.9 \%$ and $42.3 \%$, respectively. Moreover, the PFC content in the meat of swimming crabs was reduced by $17.6 \%$ after steaming. Stewing swimming crab with Korean radishes reduced the average PFC content of the crab meat by $13.3 \%$, while the PFC content of radish, which as an accessory ingredient of the stew, increased. Based on our results, the PFC content in fish cake and swimming crab meat was considered to be effectively reduced using proper cooking methods and accessory ingredients with a high fiber content. Additionally, comparing the detected amount of fish cake and swimming crab in this study with the TDI of PFOS and PFOA, the estimated intake of PFOS and PFOA still considerably lower than the threshold that may cause harm to human. 

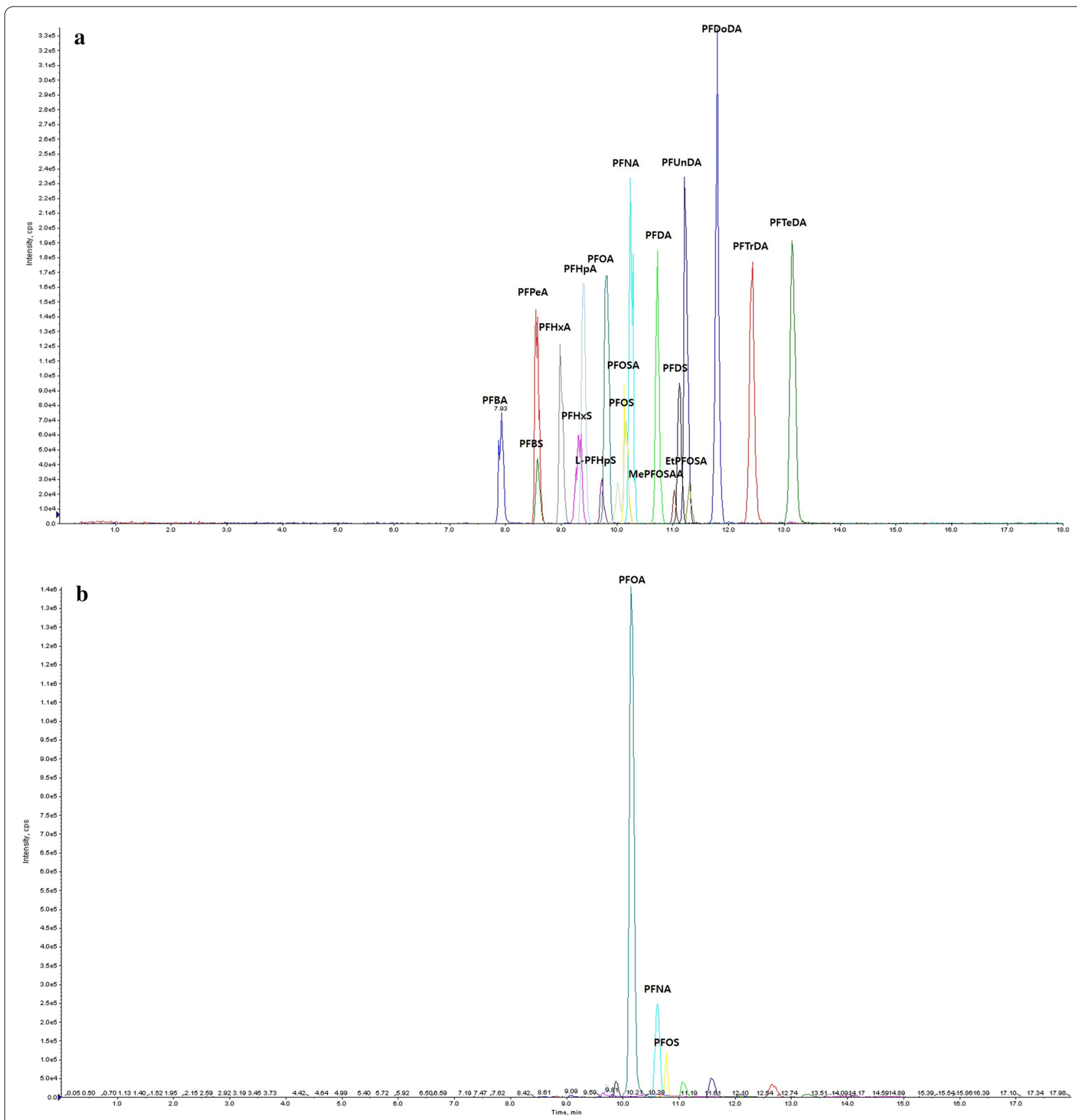

Fig. 2 LC/MS/MS chromatograms of perfluorinated compounds in standard solution (a) and broth boiled with crab meat (b). PFOA:

Perfluorooctanoic acid; PFOS: perfluorooctane sulfonate; PFBA: perfluorobutanoic acid; PFPeA: perfluorpentanoic acid; PFHxA: perfluorhexanoic acid; PFHpA: perfluorheptanoic acid; PFNA: perfluorononanoic acid; PFDA: perfluorodecanoic acid; PFUnDA: perfluoroundecanoic acid; PFDoDA: perfluorododecanoic acid; PFTrDA: perfluorotridecanoic acid; PFTeDA: perfluorotetradecanoic acid; PFBS: perfluorobutane sulfonate; PFHxS: perfluorohexane sulfonate; L-PFHpS: sodium perfluoro-1 heptanesulfonate; PFDS: perfluorodecane sulfonate; PFOSA: perfluorooctane sulfonamide; MePFOSAA: methylperfluoro-1 octanesulfonamido acetic acid; EtPFOSAA: ethyl-perfluoro-1 octanesulfonamido acetic acid 


\section{Additional file}

Additional file 1: Table S1. LOD, LOQ and R2 value of the calibration curve for perfluorinated compound content (ng/g) using LC-MSMS. Table S2. Inter- and intra-day accuracy and precision for perfluoranated compound analysis using LC-MSMS.

\section{Acknowledgements}

This research was supported by a Grant (15162KFDA077) from Korea Food and Drug Administration (2016).

\section{Authors' contributions}

Author LL performed the data analysis, interpretation, and wrote final manuscript. MJK and JP designed the experiment, collected data and assisted with the writing of the first draft of manuscript. MSC contributed to design the experimental conditions of the study. HDY, YK performed the data analysis. BKM supervised the project and revised the final manuscript. All authors read and approved the final manuscript.

\section{Availability of data and materials}

All data generated or analysed during this study are included in this published article and its Additional file.

\section{Competing interests}

The authors declare that they have no competing interests.

\section{Author details}

${ }^{1}$ Department of Food and Nutrition, Chung-Ang University, 4726 Seodong-daero, Daedeok-myeon, Anseong-si, Gyeonggi-do 456-756, Korea. ${ }^{2}$ Department of Health, Environment \& Safety, Eulji University, 553 Sanseong-daero, Sujeong-gu, Seongnam-si, Gyeonggi-do, Korea. ${ }^{3}$ Department of Food Science and Technology, Chung-Ang University, 4726 Seodong-daero, Daedeok-myeon, Anseong-si, Gyeonggi-do, Korea.

Received: 7 June 2019 Accepted: 31 July 2019

Published online: 10 August 2019

\section{References}

1. Heo JJ, Lee JW, Kim SK, Oh JE (2013) Monitoring and development of pretreatment method for perfluorinated compounds in fish samples. J Korean Soc Environ Eng 35(7):485-494

2. Espana VAA, Mallavarapu M, Naidu R (2015) Treatment technologies for aqueous perfluorooctanesulfonate (PFOS) and perfluorooctanoate (PFOA): a critical review with an emphasis on field testing. Environ Technol Innov 4:168-181

3. Hoffman K, Webster TF, Bartell SM, Weisskopf MG, Fletcher T, Vieira VM (2011) Private drinking water wells as a source of exposure to perfluorooctanoic acid (PFOA) in communities surrounding a fluoropolymer production facility. Environ Health Persp 119(1):92-97

4. Jones PD, Hu W, De Coen W, Newsted JL, Giesy JP (2009) Binding of perfluorinated fatty acids to serum proteins. Environ Toxicol Chem 22:2639-2649

5. Lin AY, Panchangam SC, Lo CC (2009) The impact of semiconductor, electronics and optoelectronic industries on downstream perfluorinated chemical contamination in Taiwanese rivers. Environ Pollut 157(4):1365-1372

6. Squadrone S, Ciccotelli V, Favaro L, Scanzio T, Prearo M, Abete MC (2014) Fish consumption as a source of human exposure to perfluorinated alkyl substances in Italy: analysis of two edible fish from Lake Maggiore. Chemosphere 114:181-186

7. European Food Safety Authority (EFSA) (2008) Perfluorooctane sulfonate (PFOS), perfluorooctanoic acid (PFOA) and their salts. Scientific opinion of the panel on contaminants in the food chain. EFSA J 653:1-131

8. Seacat AM, Thomford PJ, Hansen KJ, Olsen GW, Case MT, Butenhoff J (2002) Subchronic toxicity studies on perfluoroctanesulfonate potassium salt in cynomolgus monkeys. Toxicol Sci 68:249-264
9. Guo FF, Zhong YX, Wang YX, Li JG, Zhang JL, Liu JY, Zhao YF, Wu YN (2011) Perfluorinated compounds in human blood around Bohai Sea, China. Chemosphere 85:156-162

10. Fromme H, Tittlemier SA, Völkel W, Wilhelm M, Twardella D (2009) Perfluorinated compounds-exposure assessment for the general population in western countries. Int J Hyg Environ Health 212:239-270

11. Vestergren R, Cousins IT, Trudel D, Wormuth M, Scheringer M (2008) Estimating the contribution of precursor compounds in consumer exposure to PFOS and PFOA. Chemosphere 73(10):1617-1624

12. Meng XL, Zhang XH, Li J, Liu P (2018) Identification and comparative profiling of ovarian and testicular microRNAs in the swimming crab Portunus trituberculatus. Gene 640:6-13

13. Food and Agriculture Organization of United Nations. (2013) Portunus trituberculatus. http://www.fao.org/fishery/species/2630/en. Accessed 07 Jun 2018

14. Korea Health Industry Development Institute. National Food \& Nutrition Statistics (2013). https://www.khidi.or.kr/board/view?pageN um=63\&rowCnt $=10 \&$ menuld $=$ MENU01621\&maxIndex $=0000210124$ $9998 \&$ minlndex $=00001496139998 \&$ schType $=0 \&$ schText $=\&$ categoryld $=\&$ continent $=\&$ country $=\& u p D o w n=0 \&$ boardStyle $=\&$ no $1=310 \&$ linkl $d=178674 \&$ refMenuld=MENU00085. Accessed 11 Jun 2018

15. Naile JE, Khim JS, Hong S, Park J, Kwon BO, Ryu JS, Hwang JH, Jones PD, Giesy JP (2013) Distributions and bioconcentration characteristics of perfluorinated compounds in environmental samples collected from the west coast of Korea. Chemosphere 90(2):387-394

16. Del Gobbo L, Tittlemier S, Diamond M, Pepper K, Tague B, Yeudall F, Vanderlinden L (2008) Cooking decreases observed perfluorinated compound concentrations in fish. J Agr Food Chem 56:7551-7559

17. Butenhoff $J$, Olsen GW, Pfahles-Hutchens A (2016) The Applicability of biomonitoring data for perfluorooctanesulfonate to the environmental public health continuum. Andrea Pfahles-Hutchens. Environ Health Persp 114(11):1776-1782

18. Rural development administration of Korea (2014). http://www.koreantk com/ktkp2014/food/food-view.view?foodCd=TF10000254 and http:// koreanfood.rda.go.kr/kfi/tfSrch09/view. Accessed 23 Apr 2018

19. Bang SA, Park NY, Hwang YR, Kang GJ, Kim HJ, Kang YW, Kho YL, Kim JH (2018) Development of pretreatment method for perfluorinated compounds different groups of fat content in food. Korean J Food Sci Technol 50:14-20

20. Xiao HW, Pan ZL, Deng LZ, El-Mashad HM, Yang XH, Mujumdar AS, Gao ZJ, Zhang Q (2017) Recent developments and trends in thermal blanching - a comprehensive review. Inf Process Agric 4(2):101-127

21. Pedreschi F, Kaack K, Granby K (2004) Reduction of acrylamide formation in potato slices during frying. LWT Food Sci Technol 37(6):679-685

22. Vassiliadou I, Costopoulou D, Kalogeropoulos N, Karavoltsos S, Sakellari A, Zafeiraki E, Dassenakis M, Leondiadis L (2015) Levels of perfluorinated compounds in raw and cooked Mediterranean finfish and shellfish. Chemosphere 127:117-126

23. Kong XZ, Liu WX, He W, Xu FL, Koelmans AA, Mooij WM (2018) Multimedia fate modeling of perfluorooctanoic acid (PFOA) and perfluorooctane sulphonate (PFOS) in the shallow lake Chaohu, China. Environ Pollut 237:339-347

24. Wang Q, Zhang Z, Ruan YF, Li J, Sun HW, Zhang G (2018) Occurrence and distribution of perfluorooctanoic acid (PFOA) and perfluorooctanesulfonic acid (PFOS) in natural forest soils: a nationwide study in China. Sci Total Environ 645:596-602

25. Lindim C, Van Gils J, Cousins IT (2016) Europe-wide estuarine export and surface water concentrations of PFOS and PFOA. Water Res 103:124-132

26. Zhang NC, Gao YQ, Tong LT, Li ZG (2018) Superheated steam processing improved the qualities of oats flour and noodles. J Cereal Sci 83:96-100

27. Alves RN, Maulvault AL, Barbosa VL, Cunha S, Kwadijk CJAF, ÁlvarezMuñoz D, Rodríguez-Mozaz S, Aznar-Alemany Ò, Eljarrat E, Barceló D, Fernandez-Tejedor M, Tediosi A, Marques A (2017) Preliminary assessment on the bioaccessibility of contaminants of emerging concern in raw and cooked seafood. Food Chem Toxicol 104:69-78

28. Barbosa V, Maulvault AL, Alves RN, Kwadijk C, Kotterman M, Tediosi A Fernández-Tejedor M, Sloth JJ, Granby K, Rasmussen RR, Robbens J, Witte BD, Trabalón L, Fernandes JO, Cunha SC, Marques A (2018) Effects of steaming on contaminants of emerging concern levels in seafood. Food Chem Toxicol 118:490-504 
29. Zhang RB, Zhang H, Chen QW, Luo J, Chai ZF, Shen JC (2017) Composition, distribution and risk of total fluorine, extractable organofluorine and perfluorinated compounds in Chinese teas. Food Chem 219:496-502

30. Lee SW, Kim BK, Han JA (2018) Physical and functional properties of carrots differently cooked within the same hardness-range. LWT Food Sci Technol 93:346-353

31. Jadan Piedra C, Sanchez V, Velez D, Devesa V (2016) Reduction of mercury bioaccessibility using dietary strategies. LWT Food Sci Technol 71:10-16

32. Wu D, Li XK, Zhang JX, Chen WR, Lu P, Tang YM, Li LS (2018) Efficient PFOA degradation by persulfate-assisted photocatalytic ozonation. Sep Purif Technol 207:255-261
33. The sixth and seventh Korea National Health and Nutrition Examination Survey (KNHANES VI, VII) (2014-2016) Korea Centers for Disease Control and Prevention

\section{Publisher's Note}

Springer Nature remains neutral with regard to jurisdictional claims in published maps and institutional affiliations.

\section{Submit your manuscript to a SpringerOpen ${ }^{\circ}$ journal and benefit from:}

- Convenient online submission

- Rigorous peer review

- Open access: articles freely available online

- High visibility within the field

- Retaining the copyright to your article

Submit your next manuscript at $\boldsymbol{\nabla}$ springeropen.com 